Editorial

\title{
Monitoring progress towards universal health coverage: recent developments
}

\author{
David B. Evans, ${ }^{1}$ Ties Boerma ${ }^{2}$ and Marie-Paule Kieny ${ }^{3}$
}

The concept of universal health coverage (UHC) is now well established and understood as the aspiration that all people can obtain the quality health services they need without the risk of suffering financial hardship because of the need to pay out-of-pocket. Resolutions in the World Health Assembly $(1,2)$, Regional Committees (3), and the UN General Assembly (4) have urged countries to develop their health and health financing systems to move closer to UHC. In the most recent World Health Assembly, another resolution argued that the principles of UHC should be included in the next set of sustainable development goals after 2015 (5).

This increasing interest in UHC has resulted in more than 80 country requests to $\mathrm{WHO}$ for assistance on how to modify their health systems to move closer to UHC, and increasingly countries are also asking how best to track their progress. In response, WHO has developed jointly with the World Bank a measurement framework. It draws on many inputs including: five consultations with technical experts from academia, bilateral and multilateral organizations and countries; a consultation with civil society; more than 80 written submissions; and a set of country studies that identified what can and cannot be measured easily at country level. ${ }^{1}$ The resulting framework

\footnotetext{
1 A number of these studies will be published in a forthcoming issue of PLOS Medicine.
}

is now available on-line on the web sites of both WHO and the World Bank (6).

The starting point for countries is to measure their attainment on the three dimensions of $\mathrm{UHC}$ - population coverage, coverage with needed, quality health services and coverage with financial risk protection. It is not practical for countries to measure coverage of all the possible health services that their population needs, so the framework document recommends that countries define a set of tracer conditions that meet a set of criteria defined in Box 1 . They will differ according to a country's health problems and capacity to measure.

Two indicators of the lack of financial protection, the second dimension, are widely used - the incidence of impoverishment resulting from out-of-pocket health payments and the incidence of financial catastrophe. Other indicators such as the extent to which people are pushed further into poverty and the severity of financial catastrophe can also be calculated at the same time from household expenditure surveys using readily available statistical programs (7). The joint WHO/ World Bank framework recommends that countries can measure all of them if they wish, but at a minimum they need to track the proportion of the population pushed into poverty, and pushed further into poverty, by out-of-pocket health payments.

A country's achievements in terms of coverage with needed health services and financial risk protection show the average level of attainment of population coverage, the third dimension of UHC. However, average achievements are only one part of the story and inequalities in coverage also need to be measured, falling over time one hopes. The WHO/World Bank document recommends that, at a minimum, countries should monitor variations in coverage by gender, geographic area (e.g. place of residence, district) and income/wealth but they should also consider adding additional stratifications that are important in their settings.

These recommendations focus on country progress only in terms of the three dimensions of UHC. This is essential but is similar to measuring life expectancy. Life expectancy can be used to track whether health has improved or not, but by itself it does not reveal why or what policy levers can be used to do better. The same goes for UHC, so tracking progress towards UHC needs to be embedded in a broader health systems performance assessment framework that allows the assessment of key determinants of progress. The availability, quality and distribution of key inputs infrastructure, health workers of different types, medicines and other medical products, financial resources, governance and information - are part of this. Another is the outputs made available by these inputs, e.g. service readiness and quality, health service utilization and the existence of various pooling arrangements for financial risk protection. Tracking 


\section{Box 1 Criteria for selecting tracer indicators of coveragewith health services}

Tracer indicators should:

- address the major health problems faced in a country

- focus not only on the unfinished agenda of the current MDGs but also on the emerging agenda of noncommunicable diseases (including cancers and mental health) and injuries

- cover promotion, prevention, treatment, rehabilitation and palliation

- incorporate quality as much as possible

- be feasible to measure now or in the near future.

progress with inputs and outputs, along with a variety of social determinants such as educational attainment and poverty rates, allows an assessment of why progress towards UHC has improved or deteriorated and the development of strategies to do better.

Countries will also monitor improvements in the social goals to which UHC contributes - health in this case. The focus on UHC does not, therefore, imply that countries measure only the three dimensions of UHC to the exclusion of everything else. In addition, the country flexibility suggested in the WHO/World Bank framework does not mean that it is impossible to define a core set of indicators that all countries would track as part of reporting should UHC be included as part of the post-2015 development goals or targets. WHO has already proposed a set of these indicators for discussion, recognizing that the decision about the post-2015 agenda is the domain of Member States. In the end, however, the most important thing is for countries to map their own progress and devise and implement policies to move faster.

\section{References}

1. World Health Assembly Resolution WHA 58.33. Sustainable health financing, universal coverage and social health insurance In: Fifty-Eighth World Health Assembly, Geneva, 16-25 May 2005. Resolutions and decisions, annex. Geneva: World Health Organization; 2005 http://apps.who.int/gb/ebwha/ pdf_files/WHA58-RECl/english/A58_2005_RECl-en.pdf, accessed 2 July 2014).

2. World Health Assembly Resolution 64.9. Sustainable health financing structures and universal coverage. In: Sixty-Fourth World Health Assembly, Geneva, 16-24 May 2011. Resolutions and decisions, annex. Geneva: World Health Organization; 2011(http://apps.who.int/gb/ebwha/pdf_files/ WHA64-REC1/A64_REC1-en.pdf\#page $=21$, accessed 2 July 2014).

3. WHO Regional Committee for the Eastern Mediterranean EM/RC59/R.3 of 2012 on health systems strengthening in countries of the Eastern Mediterranean Region: challenges, priorities and options for future action. Cairo, World Health Organization Regional Office for the Eastern Mediterranean; 2012 (http://applications.emro.who.int/docs/RC_Resolutions_2012_3_14693_EN.pdf, accessed 2 July 2014).

4. Sixty-seventh session of the United Nations General Assembly 2012A/67/L.3 A/67/L.36 . Global health and foreign policy (http://ncdalliance.org/sites/default/files/resource_files/ Global\%20Health\%20and\%20Foreign\%20Policy\%20resolution\%202012_67th\%20GA.pdf, accessed 2 July 2014).

5. World Health Assembly Resolution 67.14. Health in the post2015 development agenda. In: Sixty-Seventh World Health Assembly, Geneva, 16-25 May 2014. Geneva: World Health Organization; 2014 (http://apps.who.int/gb/ebwha/pdf_files/ WHA67/A67_R14-en.pdf, http://applications.emro.who.int/ docs/RC_Resolutions_2012_3_14693_EN.pdf, accessed 2 July 2014).

6. Monitoring progress towards universal health coverage at country and global levels: framework, measures and targets. Geneva: World Health Organization and International Bank for Reconstruction and Development/The World Bank; 2014 (http://apps.who.int/iris/bitstream/10665/112824/1/WHO_ HIS_HIA_14.1_eng.pdf?ua=1, accessed 2 July 2014).

7. World Bank Group. ADePT software platform (http://econ. worldbank.org/WBSITE/EXTERNAL/EXTDEC/EXTRESEARCH/ EXTPROGRAMS/EXTADEPT/0, contentMDK:22595675 m enuPK:7108374 pagePK:64168176 piPK:64168140 theSite PK:7108360,00.html, accessed 2 July 2014) 